\title{
Recent Evidence for the Association of Initiator with Counter Ion in Cationic Polymerization
}

\author{
Pierre SigWalt and Georges SAUVET \\ Université Pierre et Marie Curie, Laboratoire de Chimie Macromoléculaire, \\ 4, Place Jussieu, 75230 Paris, Cedex 05, France.
}

(Received April 15, 1980)

\begin{abstract}
Spectroscopic studies (by UV and NMR) of the reaction of 1,1-diphenylethylene with trifluoromethanesulfonic acid have been made in dichloromethane, at temperatures $\left(-30^{\circ} \mathrm{C}\right.$ to $-90^{\circ} \mathrm{C}$ ) at which the carbocations are stable. A $33 \%$ average yield in carbocations with respect to $\mathrm{CF}_{3} \mathrm{SO}_{3} \mathrm{H}$ was found in a large concentration range and interpreted as a complexation of the $\mathrm{CF}_{3} \mathrm{SO}_{3}{ }^{-}$anion by 2 inactive acid molecules. For 3-phenylindene, the yield was $50 \%$. Further model studies have shown that various triflic salts $\left(\right.$ of $\left.\mathrm{Ph}_{3} \mathrm{C}^{+}, \mathrm{Bu}_{4} \mathrm{~N}^{+}, \mathrm{Ag}^{+}\right)$are strongly solvated by triflic acid, and the results are in agreement with the formation of complex counter ions of structures $\mathrm{A}^{-}(\mathrm{HA}) ; \mathrm{A}^{-}(\mathrm{HA})_{2}$ and $\mathrm{A}^{-}(\mathrm{HA})_{3}$. The implications of these results for cationic polymerizations are discussed and particularly the interpretation of various observations made in the literature about the effect of common salt addition and of a variation of the dielectric constant of the medium.

KEY WORDS Cationic Initiation / Triflic Acid / Salt Effects / Anion

Solvation / 1,1-Diphenylethylene / Trifluoromethanesulfonic Acid /

Cationic Polymerization /
\end{abstract}

The central problem of cationic polymerization of ethylenic monomers is still that of the nature and concentration of the active species, and is linked with the mechanism of initiation. It has not been really solved in the case of protonic acid initiation generally still written as a simple electrophilic proton addition on the double bond as in the pioneer work of Pepper with the styrene-sulphuric acid system. ${ }^{1}$

The system styrene-perchloric acid in various chlorinated solvents has been one of the most studied, but the kinetics are quite different at various temperatures. Near room temperature (in $\mathrm{CH}_{2} \mathrm{Cl}_{2}$ or $\mathrm{CH}_{2} \mathrm{ClCH}_{2} \mathrm{Cl}$ solution), polymerization is slow and without kinetic termination, but there is no visible species during the propagation step in the $300-450 \mathrm{~nm}$ range. In their pseudocationic theory, Gandini and Plesch ${ }^{2}$ proposed that the active invisible species are esters, but this has been challenged by other authors who suggested an equilibrium reaction giving a very low concentration of ionic species, the ester being inactive. However, the best argument for the pseudocationic theory remains that there is a very limited effect of added water on the polymerization rate. But water may inhibit the polymerization when it is premixed (in equimolar ratio) to the perchloric acid. Several kinetic data about monomer consumption are in agreement with a solvation of the active perchlorate ester by 4 styrene molecules, the propagation being written ${ }^{2}$ :

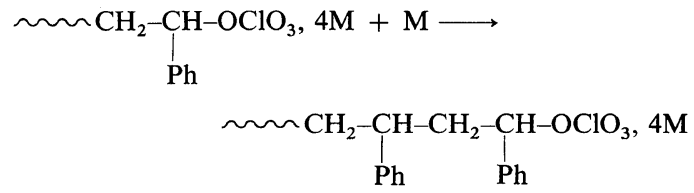

Initiation by acetyl perchlorate at $0^{\circ} \mathrm{C}$ also gave a reaction without visible species and without kinetic termination, but a bimodal molecular weight (MW) distribution was obtained for the polymer ${ }^{3}$ and attributed to the independent growth of two types of active species, a non-dissociated one, giving the lowmolecular-weight peak, and another dissociated one, giving the high molecular weights. The latter could be suppressed by addition of tetraalkylammonium perchlorate or by using solvents of lower dielectric constants. 


\section{P. Sigwalt and G. SAuvet}

Bimodal distributions were also observed with perchloric acid at $0^{\circ} \mathrm{C}$, with a reduction of the highmolecular-weight peak by salt addition. ${ }^{4}$

At low temperatures $\left(-70^{\circ} \mathrm{C}\right.$ to $-98^{\circ} \mathrm{C}$ in $\mathrm{CH}_{2} \mathrm{Cl}_{2}$ ), the kinetics are completely different, polymerization being very rapid and completed in a few seconds, with limited yields. ${ }^{4,5}$ Stopped-flow methods permitted the detection of ionic species absorbing at $340 \mathrm{~nm}$, supposed to be carbocations, but with maximum concentrations of about $1 \%$ of the initiator only. The presence of perchlorate end groups (unreactive with styrene at low temperature) is likely since block copolymers could be prepared with high yields with $N$-substituted aziridines initiated at low temperature. ${ }^{6}$ However, it should be noted that such type of end groups could not be detected by the NMR technique for polymerizations realized in $\mathrm{CCl}_{4}$ at room temperature. ${ }^{7}$

Several other features of these polymerizations by perchloric acid are not completely explained, such as the increase of the apparent $k_{\mathrm{p}_{\mathrm{app}}}$ with an increase of $[\mathrm{M}]_{0}$ and with an increase in salt concentration for the low-temperature reaction. ${ }^{4}$

More recent studies have used the strongest protonic acid available, trifluoromethanesulfonic (triflic) acid, that gives high polymerization rates even at high temperatures. Three main series of studies have been made, by Chmelir et al., Higashimura et al., and Kunitake et al.

Styrene polymerization by triflic acid $\left([\mathrm{C}] \sim 10^{-4}\right.$ mol $1^{-1}$ ) in dichloromethane solution at $-15^{\circ} \mathrm{C}^{8,9}$ was rapid and completed in a few minutes when the initiator concentration was high enough. S-shaped curves were observed for low [C]. There was also a strong negative effect of monomer concentration on the rate ${ }^{8}$ that was attributed to an inactivation of the initiator through complexation with the monomer ([M] varying between 0.05 and $0.5 \mathrm{moll}^{-1}$ ).

In order to explain the kinetic results and conductimetry experiments, initiation was supposed to occur through ionization of acid aggregates, such as

$$
(\mathrm{HA})_{2} \rightleftharpoons \mathrm{H}_{2} \mathrm{~A}^{+}+\mathrm{A}^{-}
$$

Similar results were observed by Higashimura $e t$ al., ${ }^{10}$ who, however, found a strong positive effect of an increase of the dielectric constant of the medium on the rate constant $k_{\mathrm{p}}$ and attributed the monomer concentration effect to this phenomenon. These authors also found a decrease of $k_{\mathrm{p}}$ on the addition of $\mathrm{Bu}_{4} \mathrm{~N}^{+}, \mathrm{SO}_{3} \mathrm{CF}_{3}{ }^{-}$to the system. But this effect did also occur in benzene, showing that a simple "salt effect', could not explain all the results. For dielectric constants of about $6-8$, bimodal distributions were obtained for the polymer, and attributed to the presence of two types of independent active species, dissociated and non-dissociated. Unimodal distributions were obtained for low (benzene) and high (nitrobenzene) dielectric constants.

The use of stopped-flow experiments permitted the observation of transient cationic species in the system styrene- $\mathrm{CF}_{3} \mathrm{SO}_{3} \mathrm{H}-\mathrm{CH}_{2} \mathrm{Cl}_{2}{ }^{11}$ by recording of rapid-scan spectra. A peak at $340 \mathrm{~nm}$ was attributed to the polystyryl cation, and had very short lifetimes of $200-300 \mathrm{~ms}$ at $30^{\circ} \mathrm{C}$. The maximum concentration $\left[\mathrm{P}^{+}\right]_{\max }$ observed was about $1 \%$ of $\mathrm{CF}_{3} \mathrm{SO}_{3} \mathrm{H}$. From the visible active species concentrations $k_{\mathfrak{p}}$ values could be obtained $\left(2 \times 10^{5}-\right.$ $4 \times 10^{5} \mathrm{M}^{-1} \mathrm{~s}^{-1}$ at $30^{\circ} \mathrm{C}$ ). But contrarily to what was found by Higashimura et al. for the same system, bimodal distribution was not observed in this case.

Very recently, Kunitake et al. ${ }^{12}$ published the results of their investigations between $-1{ }^{\circ} \mathrm{C}$ and $30^{\circ} \mathrm{C}$, giving a positive activation energy for the propagation of $7 \mathrm{kcal} \mathrm{mol}^{-1}$. The effect of $\left[\mathrm{P}^{+}\right]_{\max }$ concentration on $k_{\mathrm{p}}$ was studied, and assuming an ion-pair-free ions equilibrium, $k_{\mathrm{p}}$ values of $0.5 \times 10^{5}$ to $1 \times 10^{5}$ were obtained at $0^{\circ} \mathrm{C}$. The effect on $k_{\mathrm{p}}$ of an addition of a common ion salt $\left(\mathrm{Bu}_{4} \mathrm{~N}^{+}\right.$, $\mathrm{CF}_{3} \mathrm{SO}_{3}{ }^{-}$) was also studied, and assuming a straightforward concentration effect of $\mathrm{Bu}_{4} \mathrm{~N}^{+}$, $\mathrm{CF}_{3} \mathrm{SO}_{3}{ }^{-} k_{\mathrm{p}}(+)$ (about $3 \times 10^{5}$ at $0^{\circ} \mathrm{C}$ ) and $k_{\mathrm{D}}$ of the ionic species $\left(\sim 2 \times 10^{-6}\right.$ at $\left.0^{\circ} \mathrm{C}\right)$ could be calculated (with an estimated dissociation constant $K_{\mathrm{s}}=5 \times 10^{-5}$ for the ammonium salt). However, a very strange result was obtained for the activation energy on free ions: $E_{\mathrm{p}}( \pm)=14 \mathrm{kcal} \mathrm{mol}^{-1}$ (whereas the activation energy on ion-pairs was $\left.E_{\mathrm{p}}( \pm)=5 \mathrm{kcal} \mathrm{mol}^{-1}\right)$. The first value looks quite unlikely if one compares those obtained for cationic polymerizations under radiation.

It should be observed that in most studies ${ }^{10-13}$ the initiator was used without further purification, and that in one case ${ }^{10}$ the water concentration was estimated to be $c a .3 \times 10^{-4} \mathrm{moll}^{-1}$ which was of the same order as that of the initiator.

Another recent study is that of $p$-methoxystyrene polymerization by stopped-flow methods. ${ }^{13}$ The 
active centers for this monomer were known to be much more stable than for styrene ${ }^{14}$ near room temperature and the maximum $\left[\mathrm{P}^{+}\right]_{\max }$ was observed at $30^{\circ} \mathrm{C}$ for longer times and with much higher concentrations. This permitted the measurement of $k_{\mathrm{p}}$ on these visible species (about $10^{5} \mathrm{M}^{-1} \mathrm{~s}^{-1}$ ). The catalyst efficiency $\left(\left[\mathrm{P}^{+}\right]_{\max } /\left[\mathrm{CF}_{3} \mathrm{SO}_{3} \mathrm{H}\right]\right)$ varied from 36 to $42 \%$ in $\mathrm{CH}_{2} \mathrm{Cl}_{2}$. Two observations were, however, made: the maximum concentration of $\mathrm{P}^{+}$ decreased considerably with the dielectric constant $D$ of the solvent, while the corresponding $k_{\mathrm{p}}$ increased when $D$ became lower. This was explained by assuming the formation, in solvents of low polarity, of active "invisible species." A similar effect was observed on the addition of a common ion electrolyte, which led to a decrease of $\left[\mathrm{P}^{+}\right]_{\max }$ intensity and to an increase of $k_{\mathrm{p}}$.

From this discussion, it may be seen that the nature, the relative proportions and the reactivities of ionic and non-ionic species involved in protonic acid-initiated polymerizations are still far from being completely understood. The very low initiation efficiency observed in some cases is particuarly intriguing.

We have thought that model studies of initiation of carbocation formation by reaction of triflic acid with 1,1-diphenylethylene (DPE), similar to those we have already carried out for Friedel-Crafts catalysts initiation, ${ }^{14-16}$ could give more precise informations about the structure of the active species, since the derived carbocations are stable in a wide temperature range. The results we shall describe show that even in this case, the efficiency of triflic acid is lower than $100 \%$, which may be explained by the inclusion of at least one unreactive acid molecule in the counter ion. The implications on cationic polymerizations of these results and of the studies of the interaction of triflic acid with various triflates shall also be discussed.

\section{EXPERIMENTAL}

\section{Materials}

1,1-Diphenylethylene and $\mathrm{CH}_{2} \mathrm{Cl}_{2}$ have been purified and stored in evacuated sealed vessels as previously described. ${ }^{17}$

3-Phenylindene was a sample prepared by Hung. ${ }^{18}$

Triflic acid was distilled under vacuum, and a middle fraction (bp $81{ }^{\circ} \mathrm{C}$ under 4 torr) was directly received in graduated tubes equipped with break seals, that were sealed. It remained prefectly colourless even after several months.

Tetrabutylammonium triflate was purified according to Higashimura et al. ${ }^{10}$

Triphenylmethyl triflate samples could not be isolated in the pure state and were studied in situ by $\mathrm{UV}$ and $\mathrm{NMR}$. $\mathrm{Ph}_{3} \mathrm{C}^{+}, \mathrm{CF}_{3} \mathrm{SO}_{3}{ }^{-}$was prepared by reacting $\mathrm{Ph}_{3} \mathrm{CCl}$ with $\mathrm{AgCF}_{3} \mathrm{SO}_{3}$ in $\mathrm{CH}_{2} \mathrm{Cl}_{2}$, and $\mathrm{Ph}_{3} \mathrm{C}^{+},\left(\mathrm{CF}_{3} \mathrm{SO}_{3}{ }^{-}, \mathrm{CF}_{3} \mathrm{SO}_{3} \mathrm{H}\right)$ was obtained by reacting $\mathrm{Ph}_{3} \mathrm{C}-\mathrm{OH}$ with triflic anhydride.

\section{Spectrophotometry}

Measurements were performed under vacuum in sealed vessels, using Cary 15 and Cary 118C spectrophotometers.

The initiation reaction was followed using an apparatus for relatively fast spectrophotometric measurements, ${ }^{19}$ the acid phial being broken inside the monomer solution.

The experiments measuring the initiation yield were realized using a spectrodilatometer ${ }^{15}$ permitting to determine both the cations concentration and the dimerization rate. A bulb containing an acid solution in $\mathrm{CH}_{2} \mathrm{Cl}_{2}$ was broken into the DPE solution. In another series of experiments, the acid solution was broken above the cooled monomer solution, but some acid was apparently lost by a reaction with DPE on the walls and the yields were lower (mean value of about $20 \%$ instead of $29 \%$ ).

\section{NMR Spectroscopy}

${ }^{1} \mathrm{H}$ NMR spectra were obtained from a JEOL C60HL and ${ }^{19} \mathrm{~F}$ NMR spectra from a JEOL PS 100 FT spectrophotometer. The tubes were filled in vacuum, the acid being distilled first and frozen in liquid nitrogen. Pure solvent was added and was separated from the acid by a void space. The monomer solution was then condensed on the top and the tube was sealed. The two layers of reactants could be thus melted quickly and mixed at the temperature chosen.

\section{Reactions of Alcohols with Triflic Anhydride}

Reactions were carried out in $\mathrm{CD}_{2} \mathrm{Cl}_{2}$ directly in the NMR tubes, alcohol being introduced by fractions under argon atmosphere. 


\section{REACTION OF 1,1-DIPHENYLETHYLENE WITH TRIFLIC ACID, IN DICHLOROMETHANE SOLUTION}

This reaction was studied by two different techniques in a wide concentration range.

\section{Spectrophotometric Study}

Spectrophotometric experiments were made between $-30^{\circ} \mathrm{C}$ and $-76^{\circ} \mathrm{C}$ with DPE concentrations from $3 \times 10^{-3}$ to $10^{-1} \mathrm{M}$ and $\mathrm{CF}_{3} \mathrm{SO}_{3} \mathrm{H}$ concentrations from $1.5 \times 10^{-4}$ to $12 \times 10^{-4} \mathrm{M}$.

In a few experiments, the initiation reaction was followed using the apparatus for fast spectrophotometric measurements, ${ }^{19}$ but it could not follow the rate of initiation. This is in agreement with the value of $k_{\mathrm{i}}=(3-4) \times 10^{3} \mathrm{M}^{-1} \mathrm{~s}^{-1}$ found by Kunitake at $30^{\circ} \mathrm{C}$ by a stopped-flow method. A maximum constant yield in carbocations was obtained in a few seconds, and did not vary during the polymerization of DPE.

The results of experiments made with the spectro-
Table I. Initiation of DPE by $\mathrm{CF}_{3} \mathrm{SO}_{3} \mathrm{H}$ at $-30^{\circ} \mathrm{C}$ (Spectrophotometric Experiments)

\begin{tabular}{|c|c|c|c|}
\hline$[\mathrm{M}]_{0} \times 10^{3}$ & {$[\mathrm{HA}]_{0} \times 10^{4}$} & {$\left[\mathrm{C}^{+}\right]_{\max } \times 10^{4}$} & Yield \\
\hline $\operatorname{mol} 1^{-1}$ & $\operatorname{mol~1} 1^{-1}$ & $\operatorname{mol~1}{ }^{-1}$ & $\%$ \\
\hline 170 & 1.49 & 0.362 & 24.3 \\
\hline 112 & 6.03 & 1.53 & 25.4 \\
\hline 34.2 & 6.35 & 2.25 & 35.4 \\
\hline 167 & 10.60 & 3.08 & 29.1 \\
\hline
\end{tabular}

dilatometer (introduction of the acid in the liquid phase) are given in Table I (temp, $-30^{\circ} \mathrm{C}$ ). The yields in carbocations with respect to the acid introduced have a mean value of $29 \%$, whatever the concentrations of monomer and acid (monomer being always in excess). An experiment made at $-76^{\circ} \mathrm{C}$ gave a similar value.

\section{Proton Magnetic Resonance Studies}

They were made between $-95^{\circ} \mathrm{C}$ and $-30^{\circ} \mathrm{C}$

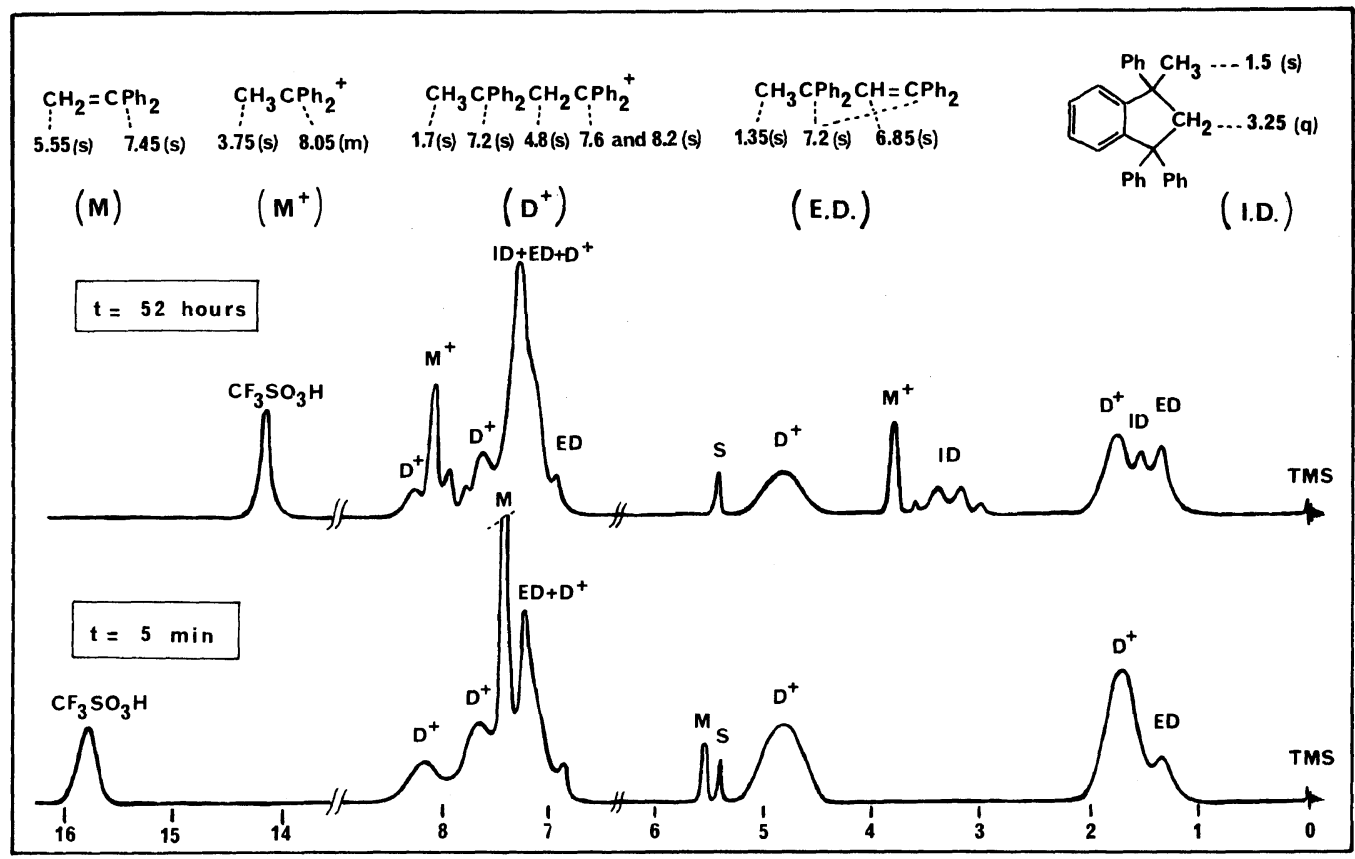

Figure 1. ${ }^{1} \mathrm{H}$ NMR spectra of the different species formed by reaction of DPE with $\mathrm{CF}_{3} \mathrm{SO}_{3} \mathrm{H}_{\text {in }} \mathrm{CD}_{2} \mathrm{Cl}_{2}$ at $-70^{\circ} \mathrm{C}$; reaction time, $5 \mathrm{~min}$ and 52 hours; $[\mathrm{DPE}]_{0}, 0.5 \mathrm{M} ;\left[\mathrm{CF}_{3} \mathrm{SO}_{3} \mathrm{H}\right]_{0}, 0.5 \mathrm{M}$. The region of aromatic protons $(6.5$ to $8.5 \mathrm{ppm})$ is not shown on the same scale. $\cdot$ The singlet $\mathrm{S}$ at $5.4 \mathrm{ppm}$ comes from residual $\mathrm{CH}_{2} \mathrm{Cl}_{2}$. 
with the much higher concentrations of 0.2 to $1.4 \mathrm{M}$ for DPE and $8 \times 10^{-2}$ to $1 \mathrm{M}$ for $\mathrm{CF}_{3} \mathrm{SO}_{3} \mathrm{H}$.

The different species that could be identified during the reaction are the monomer $(\mathrm{M})$, the monomeric cation $\left(\mathrm{M}^{+}\right)$, the dimeric cation $\left(\mathrm{D}^{+}\right)$, the ethylenic dimer (ED), and the indanic dimer (ID), as shown in Figure 1.

The variation of the concentrations of the various species with time is discussed elsewhere. ${ }^{20}$ Carbocations are formed very rapidly at the beginning of the reaction and then remain perfectly stable, but dimeric cations are formed from the beginning. Their concentration then decreases whereas the concentration of monomeric cations increases with time, the sum remaining constant (see Figure 2).

The concentration of unreacted acid is determined from the absorption at $17.3 \mathrm{ppm}$ (at $-80^{\circ} \mathrm{C}$ ) and remains also constant. A rapid change of this chemical shift to $14.4 \mathrm{ppm}$ should be noted at the end of the monomer consumption. This value is consistent with that observed for mixtures of an ionic triflate with triflic acid in $1: 2$ proportion, and is quite different from the $11.0 \mathrm{ppm}$ value for the acid alone in the same solvent. This behaviour is reminiscent of what was described by Gandini and Plesch for perchloric acid: a rapid consumption of the last styrene molecules, supposed to solvate the active centres, with a change in their nature.

The yield of initiation $Y$ was calculated according to the equation

$$
Y=\frac{\left[\mathrm{M}^{+}\right]+\left[\mathrm{D}^{+}\right]}{\left[\mathrm{M}^{+}\right]+\left[\mathrm{D}^{+}\right]+[\mathrm{HA}]_{\mathrm{r}}} \times 100,
$$

$\left[\mathrm{M}^{+}\right],\left[\mathrm{D}^{+}\right]$, and residual $[\mathrm{HA}]$ being obtained by NMR. The values are given in Table II. The mean value of $Y$ for 8 experiments was $33 \%$, and was very little dependent on temperature, with however higher values at the lowest temperatures.

Similar studies using the ethylenic dimer of DPE have given the same yield of initiation.

The spectrophotometric and NMR experiments thus gave similar values for the yield of initiation though the range of concentrations for NMR experiments was 1.000 times higher. The global equation for the formation of carbocations may be written

$$
\begin{gathered}
3 \mathrm{CF}_{3} \mathrm{SO}_{3} \mathrm{H}+\mathrm{CH}_{2}=\mathrm{CPh}_{2} \longrightarrow \mathrm{CH}_{3} \stackrel{+}{\mathrm{C}} \mathrm{Ph}_{2}, \\
\mathrm{CF}_{3} \mathrm{SO}_{3}{ }^{-}\left(\mathrm{HOSO}_{2} \mathrm{CF}_{3}\right)_{2}
\end{gathered}
$$
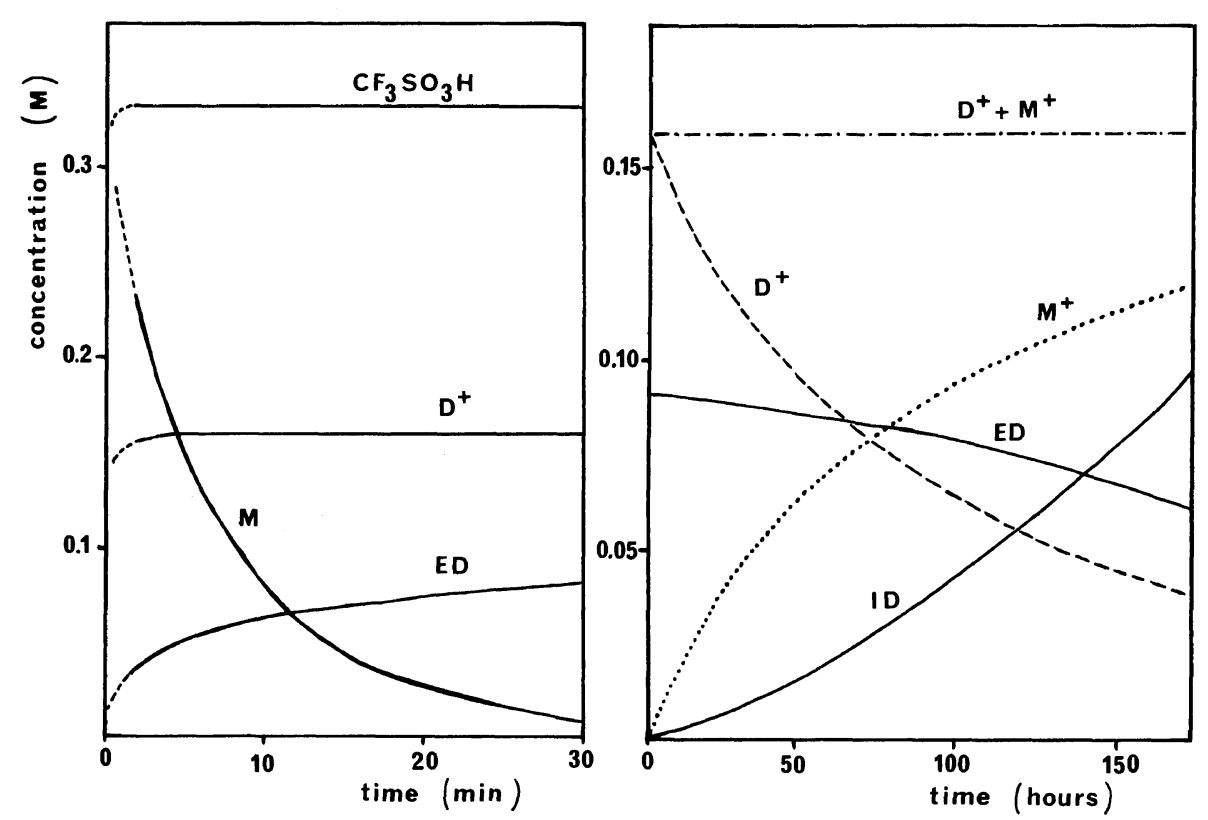

Figure 2. Evolution of the reaction of DPE with $\mathrm{CF}_{3} \mathrm{SO}_{3} \mathrm{H}$ at $-70^{\circ} \mathrm{C}: \mathrm{M}$, monomer; $\mathrm{M}^{+}$, monomeric cation; $\mathrm{D}^{+}$, dimeric cation; $\mathrm{ED}$, ethylenic dimer; ID, indanic dimer; $[\mathrm{DPE}]_{0}, 0.5 \mathrm{M} ;\left[\mathrm{CF}_{3} \mathrm{SO}_{3} \mathrm{H}\right]_{0}, 0.5 \mathrm{M}$. 
Table II. Initiation of DPE by $\mathrm{CF}_{3} \mathrm{SO}_{3} \mathrm{H}$ at low temperature. (PMR experiments)

\begin{tabular}{|c|c|c|c|c|c|c|}
\hline$|\mathrm{DPE}|_{0}$ & {$[\mathrm{HA}]_{0}$} & $T$ & $\begin{array}{c}\text { Dimeric } \\
\text { carbocation, }{ }^{\mathrm{a}}\left[\mathrm{D}^{+}\right]\end{array}$ & $\begin{array}{c}\text { Monomeric } \\
\text { carbocation, }{ }^{\mathrm{a}}\left[\mathrm{M}^{+}\right]\end{array}$ & $\begin{array}{l}\text { Unreacted } \\
\text { acid, }{ }^{\mathrm{a}}[\mathrm{HA}]_{\mathrm{r}}\end{array}$ & Yield $^{b}$ \\
\hline $\operatorname{mol~1} 1^{-1}$ & $\mathrm{~mol} \mathrm{l}^{-1}$ & ${ }^{\circ} \mathrm{C}$ & $\mathrm{mol} \mathrm{l}^{-1}$ & $\mathrm{~mol} \mathrm{l}^{-1}$ & $\mathrm{~mol} \mathrm{l}^{-1}$ & $\%$ \\
\hline 1.385 & 0.60 & -95 & 0.156 & - & 0.216 & 42.0 \\
\hline 0.879 & 0.514 & -80 & 0.150 & - & 0.296 & 33.6 \\
\hline 0.50 & 0.50 & -70 & 0.164 & - & 0.328 & 33.5 \\
\hline 1.61 & 0.361 & -50 & 0.086 & 0.035 & 0.294 & 29.0 \\
\hline 1.43 & 0.58 & -36 & 0.080 & 0.094 & 0.389 & 31.0 \\
\hline 0.224 & 0.448 & -30 & - & 0.1155 & 0.248 & 31.8 \\
\hline
\end{tabular}

a Concentrations determined by integration on the first spectrum obtained a few minutes after initiation.

b "Internal" yield of initiation, $Y=\left\{\left(\left[\mathrm{M}^{+}\right]+\left[\mathrm{D}^{+}\right] /\left[\mathrm{M}^{+}\right]+\left[\mathrm{D}^{+}\right]+[\mathrm{HA}]_{\mathrm{r}}\right)\right\} \times 100$.

One experiment has been made with 3-phenylindene at $-60^{\circ} \mathrm{C}$. The initiation was very fast. The concentration of monomeric carbocation and that of the unconsumed acid remained constant with time while the monomer was slowly consumed. The acid proton chemical shift varied from 17.7 to 15.9 ppm (linearly with monomer concentration) (see Figure 3) In this experiment, the yield of initiation was $49 \%$, which corresponded to the equation:
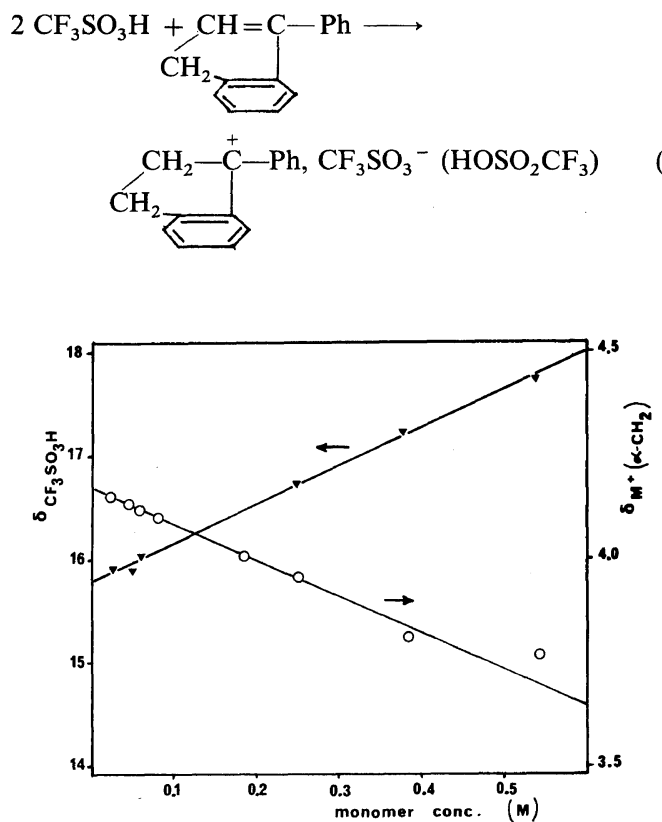

Figure 3. Reaction of 3-phenylindene with $\mathrm{CF}_{3} \mathrm{SO}_{3} \mathrm{H}$. Influence of monomer concentration on the chemical shift of unreacted-acid proton and of the $\alpha-\mathrm{CH}_{2}$ of monomeric cation. Temp, $-60^{\circ} \mathrm{C}$.
According to eq 1 and 2, the fraction of acid not consumed becomes inactive and is trapped in an adduct with the $\mathrm{CF}_{3} \mathrm{SO}_{3}{ }^{-}$moiety. A direct examination of this type of complexation is made in a following section.

\section{REACTIONS OF VARIOUS ALCOHOLS WITH TRIFLIC ANHYDRIDE}

The ${ }^{19} \mathrm{~F}$ NMR spectra of esters are quite different from those of the corresponding ionic species, and it is then possible to identify their presence or absence. The non-formation of esters during the reaction of DPE with triflic acid at low temperatures (and even after warming the solution) was concluded from the presence of a single peak for the anion (at -78.1 ppm from $\mathrm{CCl}_{3} \mathrm{~F}$ at $-85^{\circ} \mathrm{C}$ ) and no peak in the region of triflic esters ( -74 to $-77 \mathrm{ppm})$.

Attempts to synthesize various esters by the reaction of alcohols with triflic anhydride ${ }^{11}$ were not successful in the case of all tertiary alcohols investigated, but gave an ester in the case of 1phenylethanol.

\section{Triphenylmethanol + Triflic Anhydride}

Triphenylmethyl triflate presented a double maximum at $410-435 \mathrm{~nm}$ characteristic of the $\mathrm{Ph}_{3} \mathrm{C}^{+}$ cation, with an $\varepsilon_{435}=390001 \mathrm{~mol}^{-1} \mathrm{~cm}^{-1}$. ${ }^{1} \mathrm{H}$ and ${ }^{19} \mathrm{~F}$ MR confirm that no free acid is present in the solution. The single peak at $-78.3 \mathrm{ppm}$ (at room temperature) is assigned to a triflate anion solvated with a molecule of triflic acid. 


\section{$\mathrm{Ph}_{3} \mathrm{COH}+\left(\mathrm{CF}_{3} \mathrm{SO}_{2}\right)_{2} \mathrm{O} \longrightarrow$$$
\mathrm{Ph}_{3} \mathrm{C}^{+}, \mathrm{H}\left(\mathrm{OSO}_{2} \mathrm{CF}_{3}\right)_{2}{ }^{-}
$$ \\ 1,1-Diphenylethanol+Triflic Anhydride}

The reaction at room temperature give DPE and neither ester nor carbocation, with a single peak at $-79.7 \mathrm{ppm}$ in the ${ }^{19} \mathrm{~F}$ spectrum. This corresponds to the hydronium triflate $\left(\mathrm{H}_{3} \mathrm{O}\right)^{+}, \mathrm{CF}_{3} \mathrm{SO}_{3}{ }^{-}$.

The balance of the reaction is:

$$
\begin{array}{r}
3 \mathrm{Ph}_{2}\left(\mathrm{CH}_{3}\right) \mathrm{COH}+\left(\mathrm{CF}_{3} \mathrm{SO}_{2}\right)_{2} \mathrm{O} \longrightarrow \\
3 \mathrm{CH}_{3}=\mathrm{CPh}_{2}+2 \mathrm{H}_{3} \mathrm{O}^{+}, \mathrm{CF}_{3} \mathrm{SO}_{3}{ }^{-}
\end{array}
$$

\section{1-Phenylethanol + Triflic Anhydride}

The reaction carried out at $-20^{\circ} \mathrm{C}$ gave an ester $(\delta=-74.5 \mathrm{ppm})$ and an ionized compound $(\delta=-78.7 \mathrm{ppm})$ in equal amount.

The reaction is probably

$$
\begin{gathered}
2 \mathrm{Ph}\left(\mathrm{CH}_{3}\right) \mathrm{CHOH}+\left(\mathrm{CF}_{3} \mathrm{SO}_{2}\right)_{2} \mathrm{O} \longrightarrow \\
\mathrm{Ph}\left(\mathrm{CH}_{3}\right) \mathrm{CHOSO}_{2} \mathrm{CF}_{3}+ \\
\mathrm{Ph}\left(\mathrm{CH}_{3}\right) \mathrm{CHOH}_{2}^{+}, \mathrm{CF}_{3} \mathrm{SO}_{3}^{-}
\end{gathered}
$$

On warming the solution, the species at -74.5 ppm (ester) remained stable. This is quite interesting since the ester is a model of polystyryl triflate.

Similar results were obtained with benzyl alcohol at $-20^{\circ} \mathrm{C}$.

\section{COMPLEXATION OF VARIOUS TRIFLATES BY TRIFLIC ACID ${ }^{21}$}

In order to confirm the formation of species in which the acid molecules are trapped in an adduct of the $\mathrm{CF}_{3} \mathrm{SO}_{3}{ }^{-}$moiety, we studied the ${ }^{1} \mathrm{H}$ and ${ }^{19} \mathrm{~F}$ NMR spectra of mixtures of $\mathrm{CF}_{3} \mathrm{SO}_{3} \mathrm{H}$ with several ionic triflates: $\mathrm{Bu}_{4} \mathrm{~N}^{+}, \mathrm{CF}_{3} \mathrm{SO}_{3}^{-} ; \mathrm{Ag}^{+}, \mathrm{CF}_{3} \mathrm{SO}_{3}{ }^{-}$ and $\mathrm{Ph}_{3} \mathrm{C}^{+}, \mathrm{CF}_{3} \mathrm{SO}_{3}{ }^{-}$for increasing proportions of added salt.

$\mathrm{Ph}_{3} \mathrm{C}^{+}, \mathrm{CF}_{3} \mathrm{SO}_{3}{ }^{-}$free from solvating acid was prepared by reacting silver triflate with $\mathrm{Ph}_{3} \mathrm{CCl}$ (and studied "in situ").

\section{Proton NMR Studies}

These experiments were generally not made under vacuum except the experiment shown on Figure 4.

In deuterated dichloromethane at various temperatures $\left(-95^{\circ} \mathrm{C}\right.$ to $\left.20^{\circ} \mathrm{C}\right)$ according to the cation, the chemical shift of the acid ( 9.5 to $16.2 \mathrm{ppm}$ ) was strongly shifted downfield with the progressive addition of salt. The same curve was obtained whatever was the cation (see Figure 4) and could be analysed in three linear parts with angular points at ratios [anion]/[acid] equal to 0.5 and 1 . The first linear part corresponds to the formation of the anion $\mathrm{CF}_{3} \mathrm{SO}_{3} \mathrm{H}, \mathrm{CF}_{3} \mathrm{SO}_{3}{ }^{-}$the second one to $\left[\left(\mathrm{CF}_{3} \mathrm{SO}_{3} \mathrm{H}\right)_{2}, \mathrm{CF}_{3} \mathrm{SO}_{3}{ }^{-}\right]$. After a ratio of 1 , the chemical shift remained approximatively constant. The cations from diphenylethylene and from 3phenylindene behaved in a similar fashion.

\section{${ }^{19}$ F NMR Studies}

The ${ }^{19} \mathrm{~F}$ NMR experiments were made at $20^{\circ} \mathrm{C}$, and the variation of the chemical shift was observed as a function of the ratio [salt]/[acid + salt] since the salt as well as the acid brings $\mathrm{CF}_{3}$ groups. In all cases, only one singlet is observed between -76.3 and $-78.6 \mathrm{ppm} / \mathrm{CCl}_{3} \mathrm{~F}$ corresponding to a rapid exchange between the different species. There is again a strong change in the chemical shift as long as the $1: 1$ stoechiometry is not attained and it then remains constant for higher ratios (Figure 5). Angular points may be detected at molar fractions of $0.25,0.33$, and 0.50 . They are in agreement with the possible formation of counter-ions of structures $\mathrm{A}^{-},(\mathrm{HA})_{3} ; \mathrm{A}^{-}(\mathrm{HA})_{2}$, and $\mathrm{A}^{-}, \mathrm{HA}$. On Figure 5, the results for silver triflate are also plotted, but

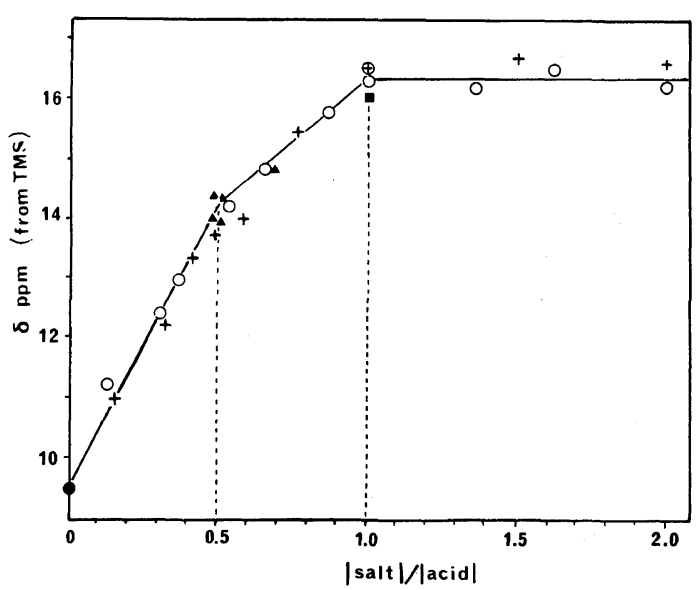

Figure 4. ${ }^{1} \mathrm{H}$ NMR: variation of the chemical shift of the acid proton for mixtures of triflic acid with various triflates in $\mathrm{CD}_{2} \mathrm{Cl}_{2}$. $\quad+, \mathrm{Ph}_{3}{ }^{+} \mathrm{CCF}_{3} \mathrm{SO}_{3}{ }^{-}$(temp, $20^{\circ} \mathrm{C}$ ); $\oplus, \quad \mathrm{Ph}_{3}{ }^{+} \mathrm{CCF}_{3} \mathrm{SO}_{3}{ }^{-}$in sealed tube (anhydrous conditions, temp, $20^{\circ} \mathrm{C}$ ); $\mathrm{O}, \mathrm{Bu}_{4}{ }^{+} \mathrm{NCF}_{3} \mathrm{SO}_{3}{ }^{-}$(temp, $20^{\circ} \mathrm{C}$ ); $\boldsymbol{\Delta}$, cation from 1,1-diphenylethylene (temp, -30 to $-95^{\circ} \mathrm{C}$ ); $\square$, cation from 3-phenylindene (temp, $-60^{\circ} \mathrm{C}$ ). 


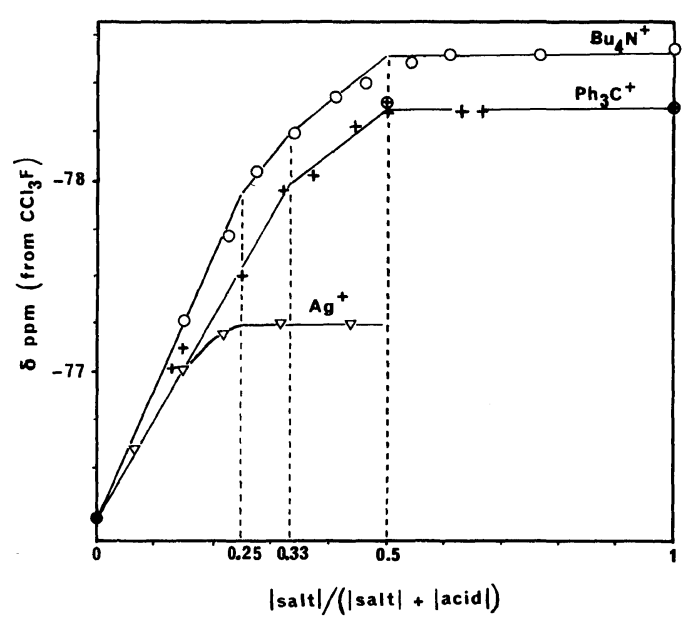

Figure 5. ${ }^{19} \mathrm{~F}$ NMR: variation of the chemical shift of the $\mathrm{CF}_{3}$ groups for mixtures of triflic acid with various triflates in $\mathrm{CD}_{2} \mathrm{Cl}_{2}$. Temp, $20^{\circ} \mathrm{C}$;,$+ \mathrm{Ph}_{3}{ }^{+} \mathrm{CCF}_{3} \mathrm{SO}_{3}{ }^{-}$; $\oplus, \mathrm{PH}_{3}{ }^{+} \mathrm{CCF}_{3} \mathrm{SO}_{3}{ }^{-}$in sealed tube (anhydrous conditions); $\mathrm{O}, \mathrm{Bu}_{4} \mathrm{~N}^{+} \mathrm{CF}_{3} \mathrm{SO}_{3}{ }^{-} ; \triangle, \mathrm{Ag}^{+} \mathrm{CF}_{3} \mathrm{SO}_{3}{ }^{-}$.

since silver triflate is soluble in $\mathrm{CH}_{2} \mathrm{Cl}_{2}$ only in the presence of an excess of triflic acid ( $3: 1$ ratio), the spectra obtained at ratios higher than 0.25 are meaningless since precipitation occurs.

\section{INFLUENCE OF COUNTER-ION COMPLEXATION ON CATIONIC POLYMERICATION}

We shall examine now, in the light of the results described here, the various problems rised by the published results relative to cationic initiation by triflic acid. The case of perchloric acid shall not be discussed in detail, since we did not make similar experiments in this case, but it will be obvious that the same kind of interpretation is often possible.

A problem that has not been mentioned so far is that a large discrepancy exists between the rates observed by Higashimura et al. and Chmelir et al. on one hand, and by Kunitake et al. on the other hand (the overall rate constants $k_{\mathrm{p}_{\text {app. }}}$ differing by a factor of several hundred). This is probably the consequence of the much higher initiator concentrations used by Kunitake et al. that exceeded largely the assumed water concentration in the medium, ${ }^{11,12}$ while Higashimura ${ }^{10}$ (and probably also Chmelir) had water concentrations of the same order of magnitude as that of the initiator. It is very likely that triflic acid hydrate $\left(\mathrm{CF}_{3} \mathrm{~S}^{-} \mathrm{O}_{3} \mathrm{H}_{3} \mathrm{O}^{+}\right)$is a much less efficient electrophile than $\mathrm{CF}_{3} \mathrm{SO}_{3} \mathrm{H}$, which leads to low initiation rates, permitting the establishment of a quasi-stationary state in the presence of enough water. When $\left[\mathrm{CF}_{3} \mathrm{SO}_{3} \mathrm{H}\right] /\left[\mathrm{H}_{2} \mathrm{O}\right]$ is higher than 1 , the faster initiation leads then to a rapid non-stationary polymerization.

But this does not explain the low initiation yields ( 1 to $3 \%$ relative to acid) observed by Kunitake $e t$ al. for styrene. The major formation of unreactive or little reactive esters would be a tentative explanation. We have found that the corresponding ester could be stable enough in some conditions, but more data on polymerizing and polymerized solutions would be necessary before coming to a conclusion.

With $p$-methoxystyrene ${ }^{13}$ the initiation yields are much higher than for styrene (36 to $42 \%$ ) and the initiation is very rapid (giving a polymerization without stationary state), which shows that the hydrate is probably a much better initiator for this very nucleophilic monomer. The catalyst concentration does not influence significantly $\left[\mathrm{P}^{+}\right]_{\max } / C_{0}$ which would be the case if water (at a constant concentration) was an inhibitor of the fast initiation. The initiator efficiency is much better explained by a complexation of acid in an unactive form, as in the case of DPE or PI, since the values found are intermediate between these two cases.

Our demonstration of the existence of these stable counter-ions in the case of monomers very reactive in the initiation step put a new light on the various results about the negative effect of salt addition on the initiator efficiency and its positive effect on the rate constants, and with similar observations made when the dielectric constant of the medium decreased.

In dichloromethane, the addition of a commonion electrolyte such as $\mathrm{Y}^{+}, \mathrm{CF}_{3} \mathrm{SO}_{3}{ }^{-}$leads to the formation of $\mathrm{Y}^{+} \mathrm{CF}_{3} \mathrm{SO}_{3}{ }^{-},\left(\mathrm{HOSO}_{2} \mathrm{CF}_{3}\right)_{n}(n=1$ or 2) and the trapped acid is not available for initiation, which lowers the initiator efficiency and also the overall rate. The higher $k_{\mathrm{p}}$ observed for the "visible species" may tentatively be explained by a similar association of the propagating species with the ammonium salt, giving a more bulky counterion and more reactive species. The formation of such aggreagates in the case of perchloric acid has been shown by Coutagne ${ }^{23}$ and the possible effect of such a complexation on styrene polymerization has already been mentioned. ${ }^{24}$ More recently, interesting data have been available about the auto- 
association of quaternary phosphonium salts, that is higher in cyclohexane than in chlorobenzene. ${ }^{25} \mathrm{We}$ have found that on the progressive addition of dimethyldodecylamine to a triflic acid solution in $\mathrm{CH}_{2} \mathrm{Cl}_{2}$, there is first a large increase of the conductivity (assigned to the formation of bulky ions of high $K_{\mathrm{D}}$ ) followed by a decrease at higher ammonium salts concentrations, showing the lower conductivity of the equimolar salt

$$
\left[\mathrm{HN}\left(\mathrm{CH}_{3}\right)_{2}\left(\mathrm{C}_{12} \mathrm{H}_{25}\right)\right]^{+}, \mathrm{CF}_{3} \mathrm{SO}_{3}{ }^{-} \text {. }
$$

With a lowering of the dielectric constant of the medium, one may expect an increase of the number of acid molecules solvating the anion, giving lower initiation yields, more bulky counter-ions and more reactive ionic species. However, we think that the situation is probably more complicated, if the active species reactivities are also modified by monomer solvation. This is suggested by the variation of the proton chemical shift in the presence of monomer, observed in the case of DPE and PI. A competition for the complexation of the various ionic species may exist between unconsumed acid and monomer. It is possible that such a competition might occur also in solvents of medium polarity such as $\mathrm{CH}_{2} \mathrm{Cl}_{2}$, that may also be involved into the equilibria.

\section{REFERENCES}

1. R. E. Burton and D. C. Pepper, Proc. R. Soc., London, Ser. A, 263, 58 (1961); M. J. Hayes and D. C. Pepper, ibid., Ser. A, 263, 63 (1961); D. C. Pepper and P. J. Reilly, ibid., Ser. A, 291, 41 (1966).

2. A. Gandini and P. H. Plesch, Proc. Chem. Soc., 240 (1964); A. Gandini and P. H. Plesch, J. Chem. Soc., 4826 (1965).

3. T. Masuda and T. Higashimura, J. Polym. Sci., B, $\mathbf{9}$, 783 (1971).

4. D. C. Pepper, Makromol. Chem., 175, 1077 (1974).
5. J. P. Lorimer and D. C. Pepper, Proc. R. Soc. London, Ser. A, 351, 551 (1976).

6. P. K. Bossaer, E. J. Goethals, P. J. Hackett, and D. C. Pepper, Eur. Polym. J., 13, 389 (1977).

7. S. D. Hamann, A. J. Murphy, D. H. Solomon, and R. I. Willing, J. Macromol. Sci., Chem., A6, 771 (1972).

8. M. Chmelir, Makromol. Chem., 176, 2099 (1975).

9. M. Chmelir, N. Cardona, and G. V. Schulz, Makromol. Chem., 178, 169 (1977).

10. T. Masuda, M. Sawamoto, and T. Higashimura, Makromol. Chem., 177, 2891 (1976); ibid., 177, 2995 (1976).

11. T. Kunitake and K. Takarabe, Polym. J., 10, 105 (1978).

12. T. Kunitake and K. Takarabe, Macromolecules, 12, 1067 (1979).

13. M. Sawamoto and T. Higashimura, Macromolecules, 11, 328 (1978).

14. G. Sauvet, J. P. Vairon, and P. Sigwalt, J. Polym. Sci., Polym. Symp., No. 52, 173 (1975).

15. G. Sauvet, J. P. Vairon, and P. Sigwalt, J. Polym. Sci., Polym. Chem. Ed., 16, 3047 (1978).

16. M. Masure, G. Sauvet, and P. Sigwalt, J. Poym. Sci., Polym. Chem. Ed., 16, 3065 (1978).

17. G. Sauvet, J. P. Vairon, and P. Sigwalt, Bull. Soc. Chim. Fr., 4031 (1970).

18. Nguyen Anh Hung, Thèse Doctorat d'Etat, Paris, 1976.

19. J. C. Favier, P. Sigwalt, and M. Fontanille, Eur. Polym. J., 10, 717 (1974).

20. A. Leborgne, D. Souverain, G. Sauvet, and P. Sigwalt, Eur. Polym. J., in press (1980).

21. D. Souverain, A. Leborgne, G. Sauvet, and P. Sigwalt, Eur. Polym. J., in press (1980).

22. M. Sawamoto, T. Masuda, and T. Higashimura, Makromol. Chem., 177, 2995 (1976).

23. D. M. Coutagne, J. Am. Chem. Soc., 93, 1518 (1971).

24. P. Sigwalt, Makromol. Chem., 175, 1017 (1974).

25. A. Landini, A. Maia, and F. Montanari, Nouv. J. Chem., 3, 575 (1979). 